International Journal of Current Advanced Research

ISSN: O: 2319-6475, ISSN: P: 2319 - 6505, Impact Factor: SJIF: 5.995

Available Online at www.journalijcar.org

Volume 6; Issue 5; April 2017; Page No. 3537-3540

DOI: http://dx.doi.org/10.24327/ijcar.2017.3540.0310

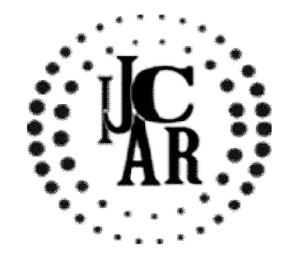

Research Article

\title{
GASTROINTESTINAL EVALUATION IN IRON DEFICIENCY ANAEMIA
}

\section{Veeraraghavan Krishnamoorthy*., Kani Shaikh Mohamed., Sabarinathan Ramanathan., Thirumoorthty., Premkumar Karunakaran., Ratnakar Kini., Pugazhendhi Thangavel and Mohammed Ali}

Institute of Medical Gastroenterology, Madras Medical College and Rajiv Gandhi Government General Hospital, Chennai, Tamil Nadu, India

\section{A R T T I C L E I N F O}

\section{Article History:}

Received $26^{\text {th }}$ January, 2017

Received in revised form $10^{\text {th }}$ February, 2017

Accepted $22^{\text {nd }}$ March, 2017

Published online $28^{\text {th }}$ April, 2017

Key words:

IDA, endoscopy, colonoscopy, video capsule endoscopy, elderly

\begin{abstract}
A B S T R A C T
Introduction: Unexplained iron deficiency anaemia in adult population is thought to be due to occult blood loss in the gastrointestinal tract.

Aim: To prospectively study the gastrointestinal lesions associated with IDA.

Materials and methods: We prospectively studied 118 consecutive patients with unexplained IDA during the study period with upper GI endoscopy. Colonoscopy was done in patients with negative findings in endoscopy. In patients were both failed to show lesions, video capsule endoscopy was done to evaluate small bowel. A questionnaire was used to study the associated GI symptoms.

Results: Upper GI endoscopy, colonoscopy and video capsule endoscopy detected lesions in $63.6 \%, 11.9 \%$ and $7.6 \%$ patients respectively. No cause was detected in $16.1 \%$ of patients. Upper GI symptoms (48.3\%) were more commonly seen than the lower $(15.3 \%)$, with heartburn and dysphagia predominating. The sensitivity and specificity of upper GI symptoms was $60 \%$ and $72 \%$ and $31 \%$ and $87 \%$ for lower GI symptoms.

Conclusion: Patients with unexplained IDA should be screened with upper GI endoscopy despite the absence of GI symptoms. IDA serves as a marker to detect newer GI malignancies.
\end{abstract}

Copyright (C2017 Veeraraghavan Krishnamoorthy et al. This is an open access article distributed under the Creative Commons Attribution License, which permits unrestricted use, distribution, and reproduction in any medium, provided the original work is properly cited.

\section{INTRODUCTION}

Iron deficiency anaemia (IDA) is one of the most common forms of anaemia prevalent in developing countries irrespective of age groups. Nonetheless, the aetiology varies in different age groups. IDA in numerous ways like reduced intake, malabsorption and chronic blood loss is coupled with the digestive system(1). Thus it contributes to a significant referral population, particularly the elderly people to gastroenterology department $(2,3)$. Chronic blood loss and decreased absorption are the most common problems encountered in this group, while menstrual blood loss is associated with pre-menopausal age group $(2,3)$. Hence, IDA necessitates comprehensive evaluation as it not only results in the success in the treatment of IDA but also helps in diagnosing hidden malignancies and other related problems at an early stage.

The role of associated gastrointestinal symptoms in referral is controversial(3). The upper and lower GIT are commonly evaluated and the role of small intestine evaluation is controversial and is reserved for individuals with persistent GI symptoms despite failing evidence in endoscopy and colonoscopy(4).

*Corresponding author: Veeraraghavan Krishnamoorthy Institute of Medical Gastroenterology, Madras Medical College and Rajiv Gandhi Government General Hospital,

Chennai, Tamil Nadu, India
GI evaluation can be done by endoscopy and radiography. Endoscopic methods comprise of esophagogastroduodenos copy (EGD),colonoscopy, enteroscopy, and wireless capsule endoscopy (WCE), whereas radiographic investigations consists of barium enema, upper GI series with or without small-bowel follow through, enteroclysis, abdominal computer tomography (CT), and CT colonography. The choice of investigation mainly relies on the availability of test, patient's condition, and the type and location of the suspected lesion(5).

\section{Aim}

To prospectively study the gastrointestinal lesions associated with IDA.

\section{MATERIALS AND METHODS}

The study was done in a tertiary care hospital in South India during the study period of January 2014 to December 2016. This cross-sectional study was done in 118 consecutive patients with IDA referred to gastro OPD for gastrointestinal evaluation. The study was approved by institute ethical committee review board. Informed and written consent were obtained from the study population. 


\section{Inclusion criteria}

Patients with unexplained iron deficiency anaemia belonging to $>13$ years but $<65$ years of age and either sex as per WHO criteria for IDA were included(6).

\section{Exclusion criteria}

Patients with obvious blood loss (melena, haematochezia, haematuria and recurrent epistaxis), pregnant women, haematological disorders like thalassemia and chronic diseases involving liver and kidney were excluded from this study.

Detection of IDA: Iron deficiency anaemia was considered if the patients had i) $\mathrm{Hb}<12 \mathrm{~g} / \mathrm{dl}$ in women and $<13 \mathrm{~g} / \mathrm{dl}$ in men; ii) serum iron less than $65 \mu \mathrm{g} / \mathrm{dl}$ and iii)serum ferritin less than $15 \mu \mathrm{g} / 1$.

GI tract evaluation: After obtaining informed and written consent, Esophagogastroduodenoscopy was done in all 118 patients in left lateral position in order to avoid aspiration. Colonoscopy was done in patients whose upper GI scopy was negative. In affordable patients with negative results in both, video capsule endoscopy was performed.

Lesions on endoscopy/colonoscopy such as erosions $(5 \mathrm{~mm}$ size), ulcers ( $>0.5 \mathrm{~cm}$ diameter), polyps $(>0.5 \mathrm{~cm}$ diameter), vascular ectasias ( 5 or more), portal hypertensive gastropathy, malignancies were considered as source of bleeding (7).

A detailed clinical history pertaining to GI symptoms were obtained. The questionnaire included NSAID intake, upper GI symptoms (dysphagia, heartburn, nausea, vomiting, upper abdominal pain and its relief by food or antacids) and lower (altered bowel habits-diarrhoea/constipation, rectal bleeding, lower abdominal pain that are coliquy or associated with altered bowel habits or relieved after passing stool or flatus).

Table 1 Results of upper and lower GI investigations in patients with IDA

\begin{tabular}{ccc}
\hline Lesions & Number & percentage \\
\hline Upper GI causes only & 7 & \\
Erosive esophagitis & 13 & $5.9 \%$ \\
Erosive gastritis & 8 & $11 \%$ \\
Erosive duodenitis & 5 & $6.8 \%$ \\
Gastric ulcer & 8 & $6.2 \%$ \\
Duodenal ulcer & 4 & $3.8 \%$ \\
Oesophageal malignancies & 5 & $4.2 \%$ \\
Gastric malignancies & 2 & $1.7 \%$ \\
Portal hypertensive gastropathy & 4 & $3.4 \%$ \\
Gastric polyps & 1 & $0.8 \%$ \\
Cameron ulcer & 18 & $15.3 \%$ \\
H.pylori gastritis & 1 & $0.8 \%$ \\
Strongyloides infection & & \\
Lower Gastrointestinal causes only & 5 & $4.2 \%$ \\
Colonic ulcer & 4 & $3.4 \%$ \\
Colonic mass & 4 & $3.4 \%$ \\
Polyp & & \\
Small bowel causes only & 2 & $1.7 \%$ \\
Hook worm infestation & 1 & $0.8 \%$ \\
Portal hypertensive polyp in jejunum & 2 & $1.7 \%$ \\
Coeliac disease & 1 & $0.8 \%$ \\
Ulcers in mid jejunum & 1 & $0.8 \%$ \\
Angioectasia in distal ileum & 2 & $1.7 \%$ \\
Erosions & 1 & \\
Both upper and lower GI lesions (1) & & $0.8 \%$ \\
Peutz-jegher syndrome & $16.1 \%$ \\
No cause detected & & \\
\hline
\end{tabular}

\section{Statistical analysis}

Data was analysed using Graph Pad software. Categorical measurements were mentioned as numbers. Mean \pm Standard
Deviation was computed for continuous variables like age, haemoglobin, serum iron and ferritin. Number of lesions were presented as percentages. Sensitivity, Specificity, Positive predictive value (PPV) \& Negative predictive value (NPV) were calculated.

\section{RESULTS}

A total of 118 patients (67 men and 51 women) with IDA were subjected to gastrointestinal evaluation by endoscopy and colonoscopy. The mean age of the study population was $57.39 \pm 6.13$ years. The mean haemoglobin, serum iron and ferritin levels were $7.58 \pm 1.4 \mathrm{~g} / \mathrm{dl}, 25.65 \pm 8.1 \mu \mathrm{g} / \mathrm{dl}$ and $13.82 \pm 3.6 \mu \mathrm{g} / \mathrm{l}$ respectively.

The Upper GI endoscopy was performed in 118 patients and lesions were detected in 75 patients $(63.6 \%)$ (Table1). Colonoscopy was done in 45 patients and detected lesions in 14 patients (11.9\%). Video capsule endoscopy done in 13 affordable patients detected lesion in 9 patients (7.6\%). Lesions in both upper and lower GI were detected in one patient. No cause was detected in 19 patients. Most of the lesions were detected in stomach (40.7\%) as shown in Fig.1.

Among the upper GI causes erosive lesions in stomach, esophagus and duodenum were more common followed by ulcers. Among malignancies diagnosed in nine patients, 2 patients had squamous cell carcinoma of upper esophagus, while the rest had adenocarcinoma (2 in esophagus, 5 in stomach). Gastric polyps and portal hypertensive gastropathy were seen in 4 and one patient respectively. In patients with negative endoscopy findings biopsies were taken and subjected to rapid urease test. RUT was positive in 18 patients showing evidence of H.pylori infection. Hiatus hernia with Cameron ulcer was seen in one patient.

In colonoscopy, colonic ulcer, mass and polyp were seen in 5, 4 and 4 patients respectively. One patient had lesions both in endoscopy and colonoscopy. Video capsule endoscopy showed features of coeliac disease in two cases. Also observed in that were polyp in jejunum, ulcers in mid jejunum, erosions, angioectasia in distal ileum and hookworm infestation. However in 19 patients no cause could be detected.

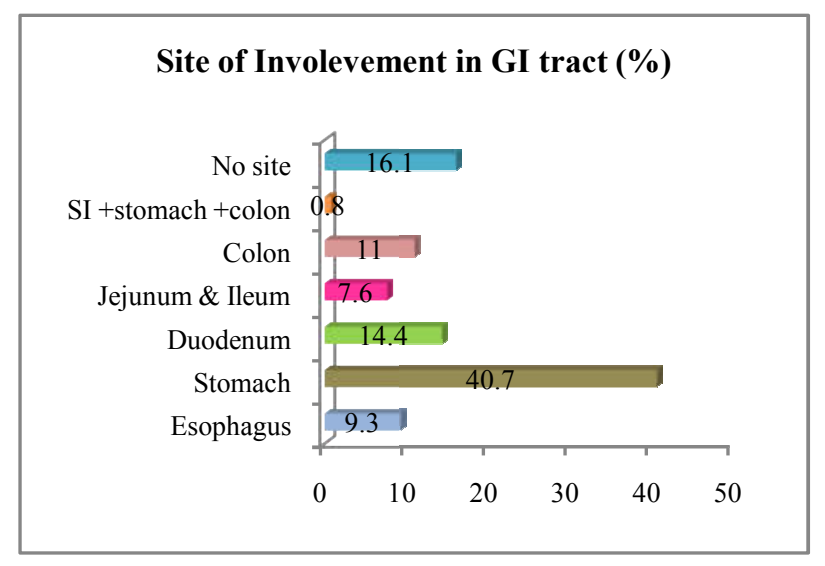

Figure 1 Site of involvement of GIT in study population (in percentage)

Symptoms associated with upper gastrointestinal symptoms were seen in $57(48.3 \%)$ patients. The most common symptom was heartburn followed by upper abdominal pain. Among these 57 patients 45 had upper GI lesion. However, upper GI lesion was also seen in 30 patients with no 
symptoms. The sensitivity, specificity, positive and negative predictive values are $60 \%, 72 \%, 79 \%$ and $51 \%$ respectively. (Table 2)

Table 2 Correlation of upper GI symptoms with upper GI disease

\begin{tabular}{cccc}
\hline \multirow{2}{*}{$\begin{array}{l}\text { Upper GI } \\
\text { symptoms }\end{array}$} & \multicolumn{3}{c}{ Upper GI disease } \\
\cline { 2 - 4 } Present & Absent & Sensitivity: 60\% \\
\hline Present & 45 & 12 & Specificity: 72\% \\
Absent & 30 & 31 & PPV: $79 \%$ \\
& 75 & 43 & NPV: $51 \%$ \\
\hline
\end{tabular}

PPV: Positive predictive value; NPV: Negative predictive value

Lower GI symptoms were seen in 18 (15.3\%) patients. Nevertheless, lower GI lesions were seen in only 4 of those with symptoms, while seen in 9 patients without any symptoms. The sensitivity, specificity, positive and negative predictive values are $31 \%, 87 \%, 22 \%$ and $91 \%$ respectively. (Table 2)

Table 3 Correlation of lower GI symptoms with lower GI disease

\begin{tabular}{cccc}
\hline $\begin{array}{c}\text { Lower GI } \\
\text { symptoms }\end{array}$ & \multicolumn{2}{c}{ Lower GI disease } & \\
Present & Absent & Sensitivity: 31\% \\
\hline Present & 4 & 14 & Specificity: $87 \%$ \\
Absent & 9 & 91 & PPV: $22 \%$ \\
& 13 & 105 & NPV: $91 \%$ \\
\hline
\end{tabular}

PPV: Positive predictive value; NPV: Negative predictive value

\section{DISCUSSION}

Idiopathic IDA contributes to majority of referral population to gastric outpatient department. They were evaluated by upper GI endoscopy, followed by colonoscopy and video capsule endoscopy in few cases. We observed $63.6 \%$ and $11.9 \%$ of patients had lesions consistent with blood loss in upper and lower GI respectively. In a study by Kepczyk, $56 \%$ of patients and $30 \%$ of patients showed lesions in EGD and colonoscopy respectively (8). Only one case in our study had lesions in both, whereas, $17 \%$ had lesions both in upper and lower GI tract in a study by Kepczyk (8). Cook et al., also showed that $16 \%$ of patients with benign upper gastrointestinal lesions had coincidental colonic lesions(9). We have not done colonoscopy for all cases and this could contribute to this major difference when compared with these two studies.

Small bowel lesions were detected in $7.6 \%$ of the study population. Majority of the studies on this aspect have not done small bowel evaluation. However, it is mentioned that $75 \%$ of those with negative results on both upper and lower GI scopy show lesions in small bowel, as it is shown in this study $(5,10)$.

As a part of investigation of IDA, malignancies were newly detected in 13 cases (stomach-5, Esophagus-4, Colon-4) in our study. Similarly, in a study by Stephen's et al., 44 and 111 patients were newly diagnosed with upper and lower GI malignancies respectively (3). Thus IDA stands as a marker of malignancy in certain number of cases.

In our study, symptoms and signs of upper and lower GI symptoms had sensitivity of $60 \%$ and $31 \%$, and a specificity of $72 \%$ and $87 \%$ for upper and lower GI lesions respectively. A study by Mcintyre also had a sensitivity and specificity of upper gastrointestinal disease of $50 \%$ and $83 \%$ respectively, and $44 \%$ and $80 \%$ for colonic disease (11). Also shown in studies is that GI lesions are detected more in number in asymptomatic individuals $(85 \%)$ than in those with symptoms $(70 \%)(12-15)$. Thus it is shown that these symptoms are not good indicators of the likely site of a lesion causing anaemia, thereby suggesting the need of endoscopy on all patients with IDA. In contrast, Stephen's et al in their study concluded that in patients presenting with IDA, in the absence of upper GI symptoms, lower GI tract should be first investigated or both gastroscopy and colonoscopy should be performed at the same time (3). They stated this as it would not only reduce the need for two separate procedure timings, but would also enable earlier diagnosis of colorectal cancer in patients presenting with IDA.

\section{CONCLUSION}

Patients with unexplained IDA should be screened with upper GI endoscopy despite the absence of GI symptoms. This not only helps in identifying and correcting the cause for anaemia, but also serves as a chance to diagnose hidden GI lesions, so that they are treated at early stages.

\section{References}

1. Chulilla JM, Colás MR, Martín MG. Classification of anemia for gastroenterologists. World J Gastroenterol. 2009;15(37):4627-37.

2. Goddard AF, James MW, McIntyre AS, Scott BB. Guidelines for the management of iron deficiency anaemia. Gut. 2011;gut-2010.

3. Stephens MR, Hopper AN, White SR, Jugool S, Stratford R, Lewis WG, et al. Colonoscopy first for iron-deficiency anaemia: a Numbers Needed to Investigate approach. Qjm. 2006;99(6):389-395.

4. Rockey DC. Gastrointestinal tract evaluation in patients with iron deficiency anemia. In: Seminars in gastrointestinal disease 1999; p. 53-64.

5. Zhu A, Kaneshiro M, Kaunitz JD. Evaluation and treatment of iron deficiency anemia: a gastroenterological perspective. Dig Dis Sci. 2010; 55(3):548-559.

6. WHO, 2001. Iron deficiency anaemia: assessment, prevention and control: a guide for programme managers.

7. Majid S, Salih M, Wasaya R, Jafri W. Predictors of gastrointestinal lesions on endoscopy in iron deficiency anemia without gastrointestinal symptoms. $B M C$ Gastroenterol. 2008;8(1):1.

8. Kepczyk MT, Kadakia CSC. Prospective evaluation of gastrointestinal tract in patients with iron-deficiency anemia. Dig Dis Sci. 1995;40(6):1283-1289.

9. Cook IJ, Pavli P, Riley JW, Goulston KJ, Dent OF. Gastrointestinal investigation of iron deficiency anaemia. Br Med J Clin Res Ed. 1986;292(6532):13801382.

10. Morris AJ, Wasson LA, MacKenzie JF. Small bowel enteroscopy in undiagnosed gastrointestinal blood loss. Gut. 1992;33(7):887-889.

11. McIntyre AS, Long RG. Prospective survey of investigations in outpatients referred with iron deficiency anaemia. Gut. 1993;34(8):1102-1107.

12. Annibale B, Capurso G, Chistolini A, D’Ambra G, DiGiulio E, Monarca B, et al. Gastrointestinal causes of refractory iron deficiency anemia in patients without 
gastrointestinal symptoms. Am $J$ Med. 2001; 111(6):439-445.

13. Gordon SR, Smith RE, Power GC. The role of endoscopy in the evaluation of iron deficiency anemia in patients over the age of 50. Am J Gastroenterol. $1994 ; 89: 1963-67$.
14. Hardwick RH, Armstrong CP. Synchronous upper and lower gastrointestinal endoscopy is an effective method of investigating iron-deficiency anaemia. $\mathrm{Br} J$ Surg. 1997;84(12):1725-1728.

15. Zuckerman G, Benitez J. A prospective study of bidirectional endoscopy (colonoscopy and upper endoscopy) in the evaluation of patients with occult gastrointestinal bleeding. Am J Gastroenterol. 1994; 87:62-66.

\section{How to cite this article:}

Veeraraghavan Krishnamoorthy et al (2017) ' Gastrointestinal Evaluation In Iron Deficiency Anaemia', International Journal of Current Advanced Research, 06(04), pp. 3537-3540.

DOI: http://dx.doi.org/10.24327/ijcar.2017.3540.0310 